\title{
ARTIGOS
}

\section{LESBIANIZAR O IRREPRESENTÁVEL}

\section{Mônica Saldanha ${ }^{1}$}

Résumo: Problemas de Gênero é referência incontornável para os estudos de gênero contemporâneos: nele, Judith Butler consolidou sua abordagem do gênero a partir da noção-derridiana de performatividade, cujos efeitos perduram nas políticas de gênero. Objetivando melhor compreender a formação do sujeito generificado e o caráter potencialmente subversivo de suas performatividades, este ensaio dedicou-se a examinar a contraposição entre os pensamentos de Monique Wittig e Luce Irigaray, apresentada por Butler no primeiro capítulo da mencionada obra. Por fim, a partir dos (des)encontros observados, questionaram-se possibilidades renovadas de uma leitura lesbiana das políticas de gênero e sexualidade.

Palavras-chave: Feminismos; Feminismos lésbicos; Psicanálise; Gênero.

\section{Introdução}

Problemas de Gênero, talvez a obra mais conhecida de Judith Butler, foi publicada pela primeira vez em 1990 e marcou a trajetória do feminismo por sua crítica às políticas feministas fundamentadas em um sujeito "mulher", bem como por sua inovadora abordagem do gênero a partir da concepção derridadiana de performatividade, cujos efeitos perduram nas políticas de gênero contemporâneas. Conforme descrevem Patrícia Porchat (2014) e Sara Salih (2015), neste texto, a filósofa de tradição hegeliana pretende dar conta da existência generificada do sujeito, empregando, para tanto, combinações teóricas singulares.

Seu impacto inegável possivelmente advém do esforço butleriano em desconstruir o par binário sexo/gênero, pilar de boa parte da teoria feminista angloamericana $^{2}$, que garante condições de possibilidade a um sujeito estável para o

\footnotetext{
${ }^{1}$ Pós-graduada lato sensu em Educação Sexual, mestranda em pela Faculdade de Educação da Universidade de São Paulo (USP) e integrante dos grupos de pesquisa Sexualidade Humana (UNISAL/Cnpq) e Estudos de Gênero, Educação e Cultura Sexual - EdGES (FEUSP/Cnpq).

${ }^{2}$ Carla Rodrigues é categórica, afirmando que o binário sexo/gênero é pilar de toda a teoria feminista (2005, p. 179); todavia, contrapõem-se a esta generalização reflexões como as de Donna Haraway (2004)
} 
feminismo, restringindo-o à sua posição humanista, consoante ao que aponta Carla Rodrigues (2005). Parece impossível, contudo, reduzir Butler a sua obra mais conhecida: como ensina Salih (2015), por compreender a produção de saberes como um processo aberto, a filósofa considera a resolução perigosamente antidemocrática e se dispõe a revisitar suas posições constantemente, "tirando proveito das lacunas de sua escrita, transformando-as em pontos de partida para futuras orientações críticas e teóricas" (SALIH, 2015, p. 14).

Sendo assim, este trabalho não pressupõe que Problemas de Gênero possa D 1 responder a todas as questões que emergem da análise do sujeito do feminismo, da categoria mulher e das políticas de identidade, tampouco que a obra constitui a contribuição final de Judith Butler ao campo do gênero. Pretende-se, tão somente, retomar a obra como um evento - no seu sentido foucaultiano - para pensar novos caminhos.

\section{Feminino: marcado ou irrepresentável}

Na visão de Firmino e Porchat (2017), em seu esforço para escapar dos paradigmas da metafísica da substância - que produzem uma posição essencialista - e do construcionismo social - que daria origem à abordagem caracterizada por Linda Nicholson (2000) como fundacionalista ${ }^{3}$-, Judith Butler apela à psicanálise para pensar formas inovadoras de concepção do sujeito. Consoante ao que discutem Butler e Gayle Rubin (2003), a psicanálises emergiu em suas obras como instrumento privilegiado para enfrentar o intratável, a persistência de determinadas características da psique humana, que não poderia ser interpretado através do aparato teórico das ciências sociais até então privilegiadas pelo feminismo.

Já no prefácio, Butler dá pistas da trajetória que seguiria e do espírito com que sua análise foi elaborada: consciente de que o poder atua na produção das categorias binárias a partir das quais se pensava o gênero até então, recusa a valência negativa imposta à noção de "problema", acolhe a ambiguidade e a indeterminação como parceiras em seu empreendimento marcadamente queer, e, a partir daí, propõe-se a

e Maira de Abreu (2016), que descrevem abordagens feministas anteriores à obra de Butler já não fundamentadas neste conceito.

3 Conforme descrito por Nicholson (2000), o fundacionalismo é uma concepção da relação entre corporalidade e subjetividade que se diferencia do determinismo biológico por reconhecer a influência social na construção da subjetividade, mas insiste em uma leitura naturalizada do corpo, que serve de fundamento para a construção de significados de gênero que apenas qualificam o sujeito. 
interrogar esta configuração de poder que nos permite falar em homens e mulheres.

Partindo de uma elaborada crítica às políticas de representação, a filósofa expõe o paradoxo do sujeito do feminismo, que só se pode fazer visível operando através dos referenciais que sustentam sua opressão e que, para fazer-se representável, produz uma universalidade fictícia - e alheia aos atravessamentos entre gênero, raça, classe e outras interseções culturais - da identidade feminina. Não propõe, entretanto, o descarte das políticas representacionais, uma vez que considera impossível posicionarse fora do campo político, das tensões de poder; sua proposta é a construção de uma D 10 genealogia feminista da categoria mulheres.

No terceiro tópico que compõe o primeiro capítulo do livro, Gênero: as ruínas instante a noção de gênero como uma dimensão de análise para investigar as abordagens feministas de seus efeitos, as marcas do gênero sobre a identidade e a subjetividade, destacadamente uma contraposição entre a apropriação de Beauvoir realizada por Wittig e a análise pós-lacaniana de Irigaray do feminino irrepresentável.

Na avaliação de Butler, a noção de feminino como irrepresentável oferece um ponto de partida para uma crítica da metafísica da substância e suas implicações no que se entende por sujeito, características de um feminismo humanista que entende o gênero como atributo de um sujeito estável, ao qual se vincularia Monique Wittig. Butler argumenta que a categoria mulheres só pode alcançar estabilidade e coerência no contexto da matriz heterossexual - "a grade de inteligibilidade cultural por meio da qual os corpos, gênero e desejos são naturalizados" (BUTLER, 2003, p. 216) - e, portanto, presumi-la como fundamento político, ainda que de forma estratégica, implica a reificação das relações de gênero (SALIH, 2015).

Para a filósofa estadunidense, ao pensar o masculino como universalidade descorporificada e o feminino como corporalidade renegada, Beauvoir reitera a cisão cartesiana entre mente e corpo e Wittig, ao incorporar acriticamente este referencial, ignora que o gênero é fundamental à noção de sujeito, que só pode tornar-se inteligível quando generificado, e persiste na proposta de alçar o sujeito feminino ao status universal, involuntariamente masculinizando-o. Este é o fundamento da afirmação butleriana de que a francesa não entra em embates com o sujeito masculino, apenas o substitui por um sujeito lésbico autodeterminado e, assim, subscreve a metafísica da substância. 
Irigaray, por sua vez, representaria uma posição feminista que compreende o gênero como “(...) um ponto relativo de convergência entre conjuntos específicos de relações, cultural e historicamente convergentes" (BUTLER, 2003, p. 29) e, indo além, percebe o feminino como um ponto de ausência linguística, portanto, impossível de ser marcado na economia significante masculinista, que inclui tanto o sujeito existencial quanto o seu Outro. Entretanto, Butler dirige a esta concepção uma crítica intensa ao seu caráter totalizante que reproduz a estratégia falocêntrica de colonização das diferenças Sob o signo do mesmo. É a partir desta percepção que Butler se recusa a pensar em um D "inimigo" singular e se volta para práticas políticas de coalizão que possam prescindir de um acordo identitário.

O grande mérito de Irigaray, para Butler, parece estar em sua percepção de que knsuancelendéstuos reelaboração da dialética do senhor e do escravo empreendida por Beauvoir e reproduzida na definição de mulher em Wittig só pode existir como produto de uma economia simbólica falocêntrica que reitera as relações de opressão, de modo que uma política feminista deve tomar a mulher como conceito aberto à ressignificação. Atrevome a insinuar, todavia, que a polêmica afirmação wittigiana de que lésbicas estão além das categorias de sexo e, portanto, não são mulheres (WITTIG, 2006, p. 57) deve-se justamente à sua percepção de que o binômio homem/mulher só emerge como efeito de uma configuração straight das relações de poder no continuum das ordens econômica, política e simbólica.

Mesmo Judith Butler indica perceber algo desta possível interpretação ao afirmar que Wittig paradoxalmente chancelaria a perspectiva foucaultiana de uma economia reguladora difusa da sexualidade, a despeito dos muitos pontos de controvérsia e contradição presentes na obra da francesa. Creio que neste paradoxo reside uma importante chave de leitura, à qual me vincularei neste ensaio, para a straight mind wittigiana como uma lógica que informa o conjunto de tecnologias da heterossexualidade - como sugere Paul Preciado (2011, p. 12) - e regula não apenas a sexualidade, mas as formas como se produzem significados, saberes e sujeitos ${ }^{4}$.

A partir desta hipótese, empenhei-me em explorar a posição de Luce Irigaray e revisitar a obra de Monique Wittig, destacadamente sob o olhar de Teresa de Lauretis

\footnotetext{
${ }^{4}$ Argumento desenvolvido no ensaio "Um conceito de deslocamentos: notas para uma leitura decolonial de The Straight Mind", apresentado como trabalho de conclusão do Curso Pensamento Lésbico Contemporâneo, realizado na Universidade Federal da Bahia (UFBA), aguardando publicação.
} 
(2003), buscando melhor compreender o sujeito generificado de Butler e o caráter potencialmente subversivo de suas performatividades.

\section{Caminhos e alternativas}

Em que pese a pertinência da comparação empreendida por Butler no contexto em que discute o lugar do feminino na economia simbólica, há que se considerar, também, os afastamentos entre Wittig e Irigaray no que concerne às suas bases D. epiștemológicas. Segundo destaca Rafael Cossi (2016) em análise das apropriações feministas do pensamento lacaniano, enquanto Butler e Irigaray servem-se da (1) 1 psicanálise como ferramenta para uma investigação profunda da construção do sujeito,

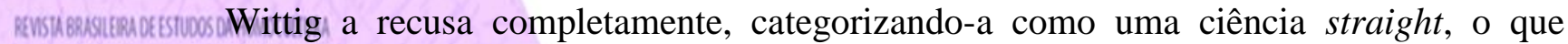
dificulta sobremaneira quaisquer paralelos entre suas análises. Seria apropriado, portanto, questionar ao que se referem Irigaray e Wittig ao retomarem os significantes "mulher" e "feminino"? Quais os afastamentos e aproximações entre as formas como autoras operam com esses significantes?

Contextualizando a trajetória de Luce Irigaray em relação ao desenvolvimento da psicanálise, Cossi aponta alguns momentos em que a autora dirige críticas a Freud e Lacan e os modos através dos quais torce seus conceitos para possibilitar a emergência de um imaginário feminino. Aos olhos do autor, Irigaray critica em Freud a compreensão da mulher em termos masculinos - como negatividade do homem - que marca a "economia do mesmo" ou "pensamento simétrico" e termina requerer à mulher a falicização para ingresso no domínio da linguagem. Este processo fálico de produção da feminilidade como mascarada submeteria uma outra feminilidade - autêntica, que caracteriza a subjetividade da mulher - à condição de irrepresentável; a mulher não está, portanto, totalmente submetida à lei fálica, é não toda. Lacan, apesar de deslocar a diferença sexual do corpo para a linguagem, incorpora esse modelo freudiano de relação homem-mulher e constitui um processo especular de formação imaginária do corpo como necessariamente masculino; nas palavras de Cossi:

O desejo passa a ser simbolizado através da linguagem: a necessidade é separada da demanda, fazendo com que o falo seja o significante da falta resultante desse processo, o significante do desejo. À mulher cabe 'ser o falo'. Para tanto, ela deve renunciar a uma parcela essencial da sua feminilidade, para a construção, processo fálico, da mascarada: é sendo o que ela não é que ela pede para, ao mesmo tempo, ser desejada e amada. Já do lado do homem, trata-se de 'ter o falo'. Ela só encontraria o significante do seu desejo no corpo do homem, que hipoteticamente o tem (COSSI, 2016, p. 41). 
Deste modo, a mulher só pode inscrever-se no discurso psicanalítico lacaniano assim como na economia simbólica do falo - como falta para o homem, nunca como üm elemento singular; o masculino é, portanto, o único sexo e o único gênero. Sendo assim, Irigaray alerta que a simples constituição de um inconsciente feminino como oposição reiteraria o regime fálico e seus binários hierarquizantes. Seria necessária uma forma positiva de pensar a diferença, que altere os modos através dos quais se entendem a alteridade e o mesmo, que perturbe os referenciais masculinos legitimados. Essa D. ruptura não poderia existir senão através da emergência de um outro real, um elemento que permitisse aos homens exceder o domínio de seu imaginário, mas, para tanto, as mulheres têm de se fazer representar para além deste imaginário masculino, daí a insistência de Irigaray no resgate-produção das representações de uma relação mãefilha.

Percebe-se que o cerne do argumento de Irigaray está na noção da economia simbólica fálica como uma forma de pensamento simétrico que produz a mulher como negatividade do homem. Em A questão do outro (2002), a autora explica que a tônica de seu raciocínio está em pensar possibilidades de subjetivação que transponham o sujeito único da filosofia ocidental, que define seus outros a partir da noção negativa de diferença, ou seja, como cópias imperfeitas de si mesmo.

\footnotetext{
Para sair do modelo todo-poderoso do um e do múltiplo, é preciso passar ao dois, um dois que não seja duas vezes o mesmo, nem um grande e um pequeno, mas dois realmente diferentes. O paradigma deste dois se encontra na diferença sexual. Por que aí? Porque aí existem dois sujeitos que não deveriam se situar em uma relação hierárquica e porque ambos têm como tarefa preservar a espécie humana e desenvolver a cultura no respeito de suas diferenças (IRIGARAY, 2002, s/p).
}

Neste ponto reside um afastamento significativo entre os pensamentos das duas feministas francesas retomadas por Butler: para romper a lógica simétrica da filosofia ocidental, Irigaray investe em uma especificidade do feminino impossível de ser definida senão nos termos da diferença sexual orientada pelo paradigma da reprodução; por outro lado, Wittig recusa a diferença sexual como um dado pré-discursivo, mas insiste na ideia de um sujeito único porque compreende gênero como um índice linguístico da diferença, que só pode marcar o espaço do outro na lógica do mesmo.

$\mathrm{Na}$ introdução de sua coletânea de ensaios El pensamiento heterosexual y otros ensayos (2006), Monique Wittig afirma seu desconforto com os usos angloamericanos do gênero; em La categoría de sexo, define mulher e homem como categorias políticas 
produzidas a partir do contrato heterossexual, desvinculando-as tanto do essencialismo biológico quanto da ideia de uma subjetividade específica; resgatando Andrea Dworkin, em No se nace mujer, reafirma a reprodução como ato de criação da fêmea: passagens que oferecem pistas para melhor compreender o gênero em Wittig.

Herdeira do feminismo francês, a teórica inscreve-se em uma abordagem da diferença sexual a partir da ideia de relações de sexagem; em outras palavras, o sexo compreendido como classes ou categorias de sexo - para Wittig não é um dado biológico, mas o efeito materializado de um processo discursivo de diferenciação que se D D formaliza no contrato heterossexual; uma taxonomia binária dos corpos que naturaliza a 17 mareação do Um e do Outro, do dominador e do dominado. Sendo assim, pode-se compreender porque Wittig considera somente a existência do sexo feminino, a

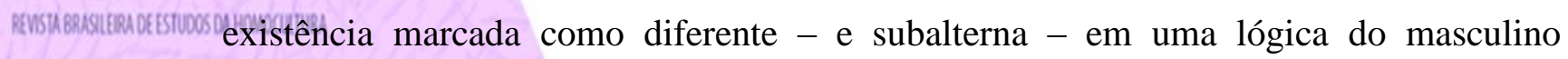
universal.

Defendo, porém, que a noção de contrato heterossexual ganha potência se for compreendido como efeito, localizado temporal e culturalmente, de uma configuração específica da economia straight do desejo (SALDANHA, 2017), minuciosamente descrita por Catharine MacKinnon em Not a moral issue (1983) e à qual Audre Lorde se oporia em Uses of the erotic (2007). Esta economia produz uma "diferença sexual" não necessariamente fundamentada no $\operatorname{corpo}^{5}$-, uma posição feminina específica em oposição simétrica - e hierarquicamente subordinada - a outra, masculina, ambas fictícias, míticas. Portanto, não há, para Wittig, uma mulher além do mito - assim como não há um homem além de seu mito -, não há uma especificidade feminina exceto aquela definida pela economia fálica do desejo. Não há, então, feminilidade que não seja justamente aquela que Irigaray caracteriza como mascarada.

Depreende-se que, assim como na psicanálise freudiana criticada por Irigaray, o feminino em Wittig aparece como negativo do masculino, porém, no pensamento da francesa, não há qualquer interesse em naturalizar e conciliar esses dois extremos. Segundo Cossi (2016), uma das críticas mais agudas de Wittig à psicanálise estaria justamente na estratégia de apagamento das condições sociais subjacentes à emergência de seus conceitos, o que naturalizaria as relações de poder nas quais eles emergem. $\mathrm{O}$

\footnotetext{
${ }^{5}$ É somente no contexto em que uma verdade do sexo se fundamenta no corpo, a assimetria implicada no binário masculino/feminino se converte em diferença sexual e o contrato heterossexual toma contornos de heterossexualidade, compreendida como orientação sexual.
} 
caráter totalizante do simbólico lacaniano impediria a produção de categorias alternativas que sirvam à desestabilização das ordens econômica e política.

Wittig localiza para além do contrato heterossexual, da economia fálica do desejo e da subjetivação marcada pela lógica do um e do múltiplo, a lésbica. Esta sugestão de Wittig, desenvolvida na parte final de The straight mind, foi tomada por Butler como uma proposta de lesbianização do mundo, de tornar o ponto de vista lesbiano o universal a partir do qual se definiriam os outros; uma inversão simples contra a qual Irigaray já havia alertado. Teresa de Lauretis oferece uma leitura

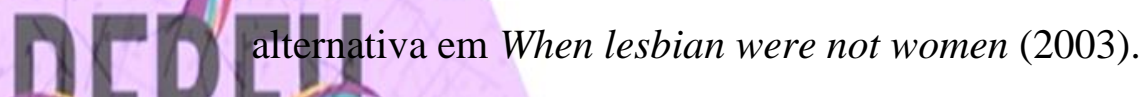

A italiana sugere que a lésbica à qual se refere Wittig não é o sujeito de uma homossexualidade em que se invertem objetos de desejo, mas um sujeito conceitual,

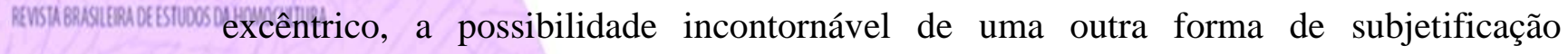
implicada na produção do sujeito straight. Lauretis identifica dois processos de deslocamento distintos na emergência da lésbica wittigiana: um identitário que, conforme aponta Cossi (2016, p. 85), pretende possibilitar a dissociação em relação à formação imaginária do mito mulher; e um erótico, que orienta o investimento em formas de relação não marcadas pela lógica straight, um investimento não apenas sexual, mas epistemológico:

\begin{abstract}
O que caracteriza o sujeito excêntrico é um deslocamento duplo: primeiro, o deslocamento psíquico de energia erótica para uma figura que excede as categorias de sexo e gênero, a figura que Wittig chamou "a lésbica"; segundo, o autodeslocamento ou desidentificação do sujeito em relação às pressuposições culturais e práticas sociais concernentes às categorias de gênero e sexo (LAURETIS, 2003).
\end{abstract}

A desidentificação é comumente referenciada como a proposta wittigiana mais marcante (PRECIADO, 2011), uma proposta localizada no campo do gênero, da identidade, do reconhecimento. O deslocamento erótico, que se refere ao campo da sexualidade, contudo, não pode ser compreendido como simples inversão de objetos, operação marcadamente straight que toma a homossexualidade como outro, cópia imperfeita, negativo da heterossexualidade; o deslocamento erótico proposto por Wittig deve passar pela reelaboração e renomeação da sexualidade, pela redefinição de suas fronteiras, em operação que se aproxima do continuum lesbiano de Adrienne Rich (2010). O incômodo de Wittig quanto à supremacia do simbólico lacaniano justifica-se, mais uma vez, nesse ponto: tomadas masculinidades e feminilidades como significantes vazios e cambiantes, completamente destacados dos contextos econômico e político no qual emergem, universaliza-se a lógica straight que os produz e turvam-se as relações 
entre gênero e sexualidade, entre a economia do desejo e a produção dos corpos sexuados.

Ao apontar a primazia das políticas de gênero em relação às políticas sexuais que tem marcado o desenvolvimento da Teoria Queer, Lauretis (2014) ressente-se justamente desta naturalização da sexualidade straight. Em sua retomada histórica, gênero e sexualidade estão em constante articulação de modo que é impossível pensar um sem o outro. Contudo, a cisão radical realizada por Gayle Rubin em Thinking sex (2011), embora tivesse seu próprio contexto e pertinência, terminou por inaugurar uma D. abordagem que prioriza as políticas de gênero, destacadamente aquelas que, por desprezarem as políticas da sexualidade, reproduzem inadvertidamente uma lógica straight.

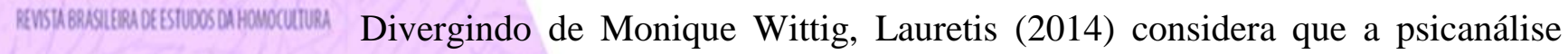
constitui ferramenta fundamental para os estudos da sexualidade e retoma Jean Laplanche para pensar a repressão da sexualidade polimorfa que dá condições de possibilidade ao vínculo social straight. A italiana explica que, na teoria da sedução generalizada de Laplanche, a sexualidade não é inata, mas o resultado de um processo de significação dos estímulos - significantes enigmáticos - recebidos pela criança de seus cuidadores e que se consolida na castração e no Édipo. Assim, a sexualidade polimorfa reprimida, incompatível com a ordem social, permanece como elemento não reconhecido e problemático da identidade e da sociedade.

Jean Laplanche também é o psicanalista escolhido por Judith Butler para fundamentar sua análise da construção do sujeito generificado. Consoante ao que descreve Porchat (2014), Butler se propõe a pensar a generificação do sujeito a partir da pulsão freudiana, de modo a possibilitar um entendimento das paródias subversivas do gênero como improvisação, sem pressupor o determinismo - social ou biológico - ou a existência de um sujeito pré-discursivo e voluntarista.

Resgatando Laplanche, Butler apropria-se do inconsciente como forma de manejar o excesso que representa a presença esmagadora e enigmática dos estímulos endereçados ao sujeito por este outro ao qual pertence a linguagem; o inconsciente é, portanto, fragmentado, incoerente, o que impossibilita a perfeita narrativa do eu, inclusive no que concerne à performatividade de gênero. Essa fragmentação é dissimulada através de um processo de purificação do sujeito que se baseia na expulsão do abjeto, produzindo a impressão de um eu coeso; contudo, esse processo só pode 
produzir uma identidade melancólica, conceito que Butler empresta de Freud, baseada em uma perda imaginada que se manifesta no corpo.

De acordo com o que ensina Salih (2015), este processo informa a lógica do Édipo freudiano, mas necessita de uma ferramenta adicional para justificar a escolha objetal, o que o aparece na obra do psicanalista como "disposição", uma característica inata que caracteriza o sujeito pré-edípico como masculino ou feminino. Butler, por sua vez, busca em Laplanche a contraposição para a versão inata da disposição freudiana: para ela, a disposição é efeito da identificação com o progenitor, não sua causa. Isto

10 implica dizer que o tabu da homossexualidade precede o tabu do incesto, de modo que a disposição para a heterossexualidade se constrói como efeito da internalização de uma proibição em que o objeto perdido - o progenitor do mesmo sexo - é instaurado no ego como identificação melancólica e, então, incorporado, de modo que a identidade de gênero orientada pela lógica heterossexual termina por constituir-se em oposição ao desejo.

Contudo, se tomarmos as interpretações de Teresa de Lauretis quanto à lésbica wittigiana como o investimento em uma economia alternativa do desejo, cabe questionar se uma problematização do tabu da homossexualidade - entendido tão somente como inversão objetal - é suficiente para abrir caminho para outras formas de subjetivação.

Não seria descabido supor que, consoante ao que aponta Lauretis (2014), a sexualidade polimorfa seja o campo no qual as políticas da sexualidade devem atuar para desestabilizar a ordem social straight. Tampouco seria desarrazoado imaginar que, se de fato toma o tabu da homossexualidade como uma questão exclusiva de escolha objetal, Butler tenha incorrido nesta mesma naturalização straight que permite pensar as políticas de gênero, políticas de representação e reconhecimento, absolutamente desconectadas das políticas da sexualidade e da problemática do desejo sexual.

\section{Considerações finais}

A contraposição entre os pensamentos de Monique Wittig e Luce Irigaray realizada por Judith Butler deixa entrever os incômodos da filósofa estadunidense em relação às limitações e impasses em que se encontrava imerso o debate feminista dos anos 1980. No entanto, ainda que critique, em Wittig, a ratificação da metafísica da substância, que se revela na reivindicação de um sujeito humano, necessariamente 
masculino; e, em Irigaray, a reprodução de uma lógica colonialista que se pretende universal, Butler reconhece, também, as contribuições de ambas as francesas, incorporando conceitos e reflexões de ambas a suas propostas iminentemente pósfeministas.

No exame deste exercício butleriano que confronta visões tão distintas, observase grande afinidade entre a straight mind wittigiana e a noção de pensamento simétrico presente nas críticas de Irigaray à psicanálise clássica, de modo que ambas esforçam-se para operacionalizar o espaço que está além, aquilo que não se pode apreender a partir D de uma economia simbólica masculina. Enquanto Irigaray aposta na emergência de um outro real que permita à mulher colocar-se como elemento de ruptura do imaginário masculino, o que sugere alcançar através da representação das relações mãe-filha, Wittig recusa os significantes de masculino e feminino, bem como as identidades de homem e mulher, para deixar emergir um espaço conceitual lésbico. Seria possível, portanto, pensar a lésbica como uma outra forma de emergência do real, não prevista por Irigaray? Há fundamento para que se pense a lésbica como irrepresentável em uma lógica fálica/straight que produz o masculino - o sujeito existencial, o Um - e o feminino - seu Outro marcado?

$\mathrm{Na}$ proposta de representação das relações mãe-filha, percebe-se um deslocamento: o investimento na representação das relações mãe-filha, que não exige a feminilidade como mascarada. Na lésbica wittigiana, como comenta Lauretis, há um duplo deslocamento: a desidentificação, que afasta a lésbica do mito da mulher, da feminilidade; e o erótico, que orienta o investimento nas relações lésbicas, nas relações não fundadas na economia straight do desejo. Irigaray argumenta, em sua análise psicanalítica, que a mulher é não-toda, ou seja, que não está totalmente submetida à lei fálica. Seria possível pensar, então, que a lésbica wittigiana, - a desertora de sua classe, refugiada que se encontra na fronteira do ser mulher (WITTIG, 2006, p. 43) representa justamente o paradoxo do feminino não-todo? Tomada a feminilidade de Wittig como sinônimo da sua versão mascarada, em Irigaray, seria possível localizar no duplo deslocamento da lésbica um ponto de convergência entre as políticas sexuais e de gênero, como desejava Lauretis?

E, por fim, considerando que tanto Butler quanto Lauretis retomam Jean Laplanche em suas análises da formação do sujeito generificado, seria descabido pensar o tabu da homossexualidade, a partir da straight mind wittigiana, para além da interdição de um objeto de desejo do mesmo sexo, reconhecendo a economia fálica do 
desejo como fundamento da ordem social straight, para retomar Wittig, ou da economia do Mesmo, nas palavras de Irigaray?

\section{Referências}

ABREU, Maira Luisa Gonçalves de. Politizando a anatomia: antinaturalismo e materialismo no pensamento feminista francês (1960-1980). 2016. 319f. Tese (Doutorado em Ciências Sociais) - Instituto de Filosofia e Ciências Humanas, Universidade Estadual de Campinas, Campinas, 2016. Disponível em: http://repositorio.unicamp.br/handle/REPOSIP/331436. Acesso em: 26 set. 2018.

BUTLER, Judith. Problemas de gênero: feminismo e subversão da identidade. Rio de Janeiro: Civilização Brasileira, 2003.

COSSI, Rafael Kalaf. A diferença dos sexos: Lacan e o feminismo. 2016. 276f. Tese kasiankelemoessuosos (Doutorado em Psicologia Clínica), Instituto de Psicologia, Universidade de São Paulo, 2016. Disponível em: http://www.teses.usp.br/teses/disponiveis/47/47133/tde25072017-090645/en.php. Acesso em 26 set. 2018.

FIRMINO, Flávio Henrique; PORCHAT, Patrícia. Feminismo, identidade e gênero em Judith Butler: apontamentos a partir de "Problemas de gênero". Doxa: Rev. Bras. Psicol. Educ., Araraquara, v. 19, n. 1, p. 51-61, 2017. Disponível em: https://periodicos.fclar.unesp.br/doxa/article/view/10819. Acesso em: 26 set. 2018.

HARAWAY, Donna. "Gênero" para um dicionário marxista: a política sexual de uma palavra. Cadernos pagu, n. 22, p. 201-246, 2004. Disponível em: http://www.scielo.br/pdf/\%0D/cpa/n22/n22a09.pdf. Acesso em: 26 set. 2018.

IRIGARAY, Luce. A questão do outro. Labrys, estudos feministas [online], n. 1-2, 2002. Disponível em: https://www.labrys.net.br/labrys1_2/irigaray1.html. Acesso em: 29 maio. 2018.

LAURETIS, Teresa de. When lesbians were not women. Labrys, Estudos Feministas, ed. especial, $2003 . \quad$ Disponível em: https://www.labrys.net.br/special/special/delauretis.htm. Acesso em: 21 dez. 2017.

Gênero e teoria queer. Buenos Aires: Universidade de Buenos Aires, 2014. (Comunicação oral). Disponível em: https://resistaorp.blog/2018/06/05/genero-e-teoriaqueer/. Acesso em: 06 de maio de 2018.

LORDE, Audre. Uses of the erotic: the erotic as power. In: Sister outsider: essays and speeches by Audre Lorde. Bekeley: Crossing Press, p. 53-59, 2007

MACKINNON, Catharine. Not a moral issue. Yale Law \& Policy Review, v. 2, p. 321, 1983. 
NICHOLSON, Linda. Interpretando o gênero. Revista Estudos Feministas, v. 8, n. 2, p. 9-41, 2000.

Disponível

em:

https://periodicos.ufsc.br/index.php/ref/article/view/11917. Acesso em: 26 set. 2018.

PORCHAT, Patrícia. Gênero é um outro. In: MINELLA, L. S.; ASSIS, G. O.; FUNK, S. B. (Org.). Políticas e fronteiras - Desafios feministas, vol. 2. Tubarão: Copiart Editora, p. 295-308, 2014.

PRECIADO, Paul. Multidões queer: notas para uma política dos "anormais". Revista Estudos Feministas, Florianópolis, v. 19, n. 1, p. 11-20, 2011. Disponível em: https://periodicos.ufsc.br/index.php/ref/article/view/S0104-026X2011000100002.

Acesso em: 26 set. 2018.

RICH, Adrienne. Heterossexualidade compulsória e existência lésbica. Bágoas Estudos gays: gêneros e sexualidades, v. 4, n. 5, p. 17-44, 2010. Disponível em: https://periodicos.ufrn.br/bagoas/article/view/2309. Acesso em: 26 set. 2018.

RODRIGUES, Carla. Butler e a desconstrução do gênero. Revista Estudos Feministas., Florianópolis, v. 13, n. 1, p. 179-183, 2005. Disponível em: https://periodicos.ufsc.br/index.php/ref/article/view/S0104-026X2005000100012.

Acesso em: 26 set. 2018.

RUBIN, Gayle; BUTLER, Judith. Tráfico sexual: entrevista. Cadernos Pagu, n. 21, p. 157-209, 2003.

RUBIN, Gayle. Thinking sex: notes on the "political economy" of sex. In:

Deviations. Durham/London: Duke University Press, p. 137-181, 2011. Disponível em: http://www.scielo.br/scielo.php?pid=S0104-

83332003000200008\&script=sci_arttext\&tlng=pt. Acesso em: 26 set. 2018.

SALDANHA, Mônica. Feminismos lésbicos e a indagação dos conceitos de erotismo e lesbianidade. In: Seminário Internacional Fazendo Gênero 11 \& 13th Women's Worlds Congress. Anais Eletrônicos, Florianópolis: UFSC, 2017. Disponível em: http://www.wwc2017.eventos.dype.com.br/resources/anais/1499392946_ARQUIVO_F eminismoslesbicoseaindagacaodosconceitosdeerotismoelesbianidade.pdf. Acesso em: 26 set. 2018.

SALIH, Sara. Judith Butler e a teoria queer. Belo Horizonte: Autêntica Editora, 2015.

WITTIG, Monique. El pensamiento heterosexual y otros ensayos. Barcelona/Madrid: Editorial EGALES, 2006.

\section{A LESBIAN APPROACH FOR THE UNREPRESENTABLE}

Abstract: Gender Trouble is an inescapable reference for contemporary gender studies since it's the book in which Judith Butler consolidated her approach for gender, grounded on Derrida's concept of performativity, whose effects linger on gender 
politics. This essay aimed to examine the contraposition of Monique Wittig's and Luce Irigaray's thoughts on the gendered subject, conducted by Butler on the book's first chapter, in order to better apprehend it's process of construction as well as subversive disposition of it's performativity. The identified points of similitude and discrepancy between the two positions enlightened possibilities of a lesbian approach for gender and sex politics.

Keywords: Unrepresentable. Feminsms. Lesbian feminisms. Psychoanalisys. Gender.

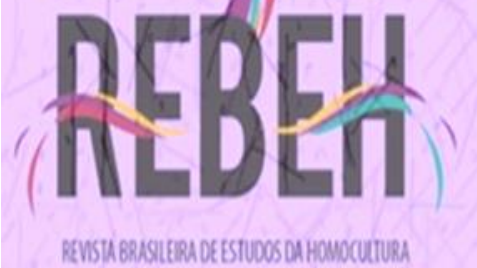

Recebido em: 26/09/2018

Aceito em: 16/10/2018 